\title{
Aplicação de FMEA e CEP para redução de sucata em uma indústria metalúrgica
}

Application of FMEA and SPC for scrap reduction in a metallurgy industry

Felipe Viana Gomes ${ }^{1}$ (Dorcid.org/0000-0002-3699-0515

Manoel Henrique Da Nóbrega Marinho ${ }^{1}$ orcid.org/0000-0003-3129-0453

${ }^{1}$ Escola Politécnica de Pernambuco, Universidade de Pernambuco, Recife, Brasil,

E-mail do autor principal: Felipe Viana Gomes felipe.vianagomes@gmail.com

RESUMO

Nos dias atuais novas metodologias vem sendo adotadas por empresas que visam se manter competitivas no mercado. A busca por melhoria contínua está presente em todas as empresas que valorizam a produtividade e qualidade de seus produtos ou serviços. Ferramentas da qualidade tem se provado úteis na resolução de problemas de qualidade. Neste trabalho foram utilizados Failure Mode and Effect Analysis (FMEA) e Controle estatístico de processo (CEP) no intuito de identificar pontos fora de controle e analisar seus impactos para então propor melhorias que possam trazer uma redução do volume de sucata em uma indústria metalúrgica. Através da aplicação dessas ferramentas foi possível reduzir o volume de sucata de 5,80\% para $1,63 \%$ ao longo de um ano no principal processo da fábrica.

PALAVRAS-CHAVE:Ferramentas da qualidade; FMEA; Controle estatístico de processo.

\section{ABSTRACT}

On current days new methodologies are being adopted by companies that seek to remain competitive. The search for continuous improvement is present in all companies that value productivity and the quality of their products or services. Quality tools have been proven useful on solving quality problems. On this paper Failure Mode and Effect Analysis (FMEA) and Statistical Process Control (SPC) have been used to identify out of control points and analyze their impacts so it would be possible to suggest improvements to reduce scraping volume in a metallurgy industry. Through the application of these tools it was possible to reduce the scrapping volume from 5,80\% to $1,63 \%$ in the main process of the factory across the year.

KEY-WORDS:Quality tools; FMEA; Statistical process control. 


\section{INTRODUÇÃO}

O setor industrial é alvo de elevada concorrência e por isso o aumento da satisfação dos clientes e a redução de custos tornam-se cada vez mais importantes para empresas que visam expandir ou se manter competitivas no mercado.

$\mathrm{Na}$ fábrica em questão, os processos iniciais envolvem o corte, punção e quinagem de chapas de aço. Como esses processos são todos realizados por máquinas automáticas ou semiautomáticas é de se esperar que um acompanhamento constante seja necessário para manter o menor nível possível de peças não conforme.

O processo de melhoria contínua de produtos e processos envolve basicamente a identificação dos problemas prioritários, observação e coleta de dados, análise e busca de causas raízes, planejamento e implementação de ações e verificação de resultados. Para auxiliar o desenvolvimento dessas ações foram criadas as várias ferramentas da qualidade [1].

Assim, o presente trabalho visa utilizar das ferramentas da qualidade e CEP utilizando os pontos fora de controle como dados de entrada para o FMEA, determinando seus impactos e propondo e aplicando melhorias.

\section{OBJETIVOS}

A seguir serão descritos os objetivos gerais e específicos da pesquisa.

\subsection{Geral}

Analisar os custos associados a sucatas em uma empresa metalúrgica por meio da aplicação de ferramentas da qualidade para identificar as principais causas e modos de falha e então propor melhorias que garantam a conformidade do processo e redução dos custos com sucata.

\subsection{Específico}

- Estratificar dados históricos relativos a desperdício de chapa na principal máquina da fábrica;

- Utilizar gráficos de controle para garantir a estabilidade do processo e aplicação de FMEA quando não conformidades forem identificadas;

- Identificar principais causas e modos de falha que levam ao sucateamento de peças;

- Estabelecer propostas exequíveis de implementação, visando à melhoria do processo e consequentemente uma redução de custos, de geração de resíduos e melhoria da qualidade.

\section{REVISÃO DA LITERATURA}

\subsection{Origem da qualidade}

Segundo Chiavenato [2], Frederick Taylor foi
um dos maiores contribuintes para o desenvolvimento da administração. Apesar das grandes margens de lucro, as empresas da época enfrentavam diversos problemas que eram refletidos na produção. Baixa produtividade, alto absenteísmo, alta rotatividade de mão-de-obra e vadiagem sistemática são alguns dos exemplos dos principais problemas observados.

Por volta dos anos 20, o estatístico Walter Shewhart começava a descrever o primeiro Gráfico de Controle para controle estatístico do processo e melhoria da qualidade [3]. No ano de 1924, Shewhart começou a introduzir o conceito de controle estatístico de processo na fábrica de Hawthorne. Ao acompanhar as características dos bens produzidos, notou que certas variações ocorriam no processo. Se essas variações fossem estatisticamente aleatórias o processo permaneceria "sob controle"; caso contrário, o processo estaria "fora de controle" e, portanto, havia alguma causa para o problema que deveria ser encontrada e eliminada [3].

De acordo Gomes [4]

Em meados dos anos 50, começou a ser desenvolvido o conceito de Gestão da Qualidade Total ou TQM a partir dos trabalhos de Feigenbaum, Juran e Deming. Deming foi um forte contribuinte para o desenvolvimento de processos estatísticos adotados pelo censo americano por volta da década de 40 , porém, dada a disponibilidade de mercado e amplas margens de lucro disponíveis após a segunda guerra mundial as empresas norte-americanas voltaram a utilizar as técnicas da administração convencional, o que fez Deming aceitar o convite de ir ao Japão ajudar a restaurar a indústria desse país, possibilitando-o de divulgar os conceitos de melhoria contínua e controle estatístico de 
processos iniciados por Shewhart. Além disso, ainda defendeu a utilização do controle da qualidade em todas as áreas da empresa e do envolvimento da alta administração para melhorias na qualidade.

A qualidade em seus primórdios era relacionada apenas à conformidade do produto, já na atualidade a mesma está diretamente relacionada ao sucesso da organização, deixando de ter um aspecto apenas corretivo e passando a ter uma abordagem de visão sistêmica.

\subsection{Ferramentas da qualidade}

De acordo com Carpinetti [1], ferramentas da qualidade têm se mostrado úteis à identificação e resolução de problemas. Além disso, diversas ferramentas podem ser combinadas para facilitar a tomada de decisão e a implementação das melhorias.

As ferramentas da qualidade podem ser usadas para coleta, processamento e disposição de informações, tanto de forma qualitativa como de forma quantitativa. Neste trabalho, serão utilizadas ambas, destacando as ferramentas FMEA (qualitativo e quantitativo) e Gráficos de controle (quantitativo).

\subsubsection{FMEA}

Segundo Helman e Andery [5], FMEA é um método de análise de projetos (de produtos ou processos, industriais e/ou administrativos) utilizado para identificar todos os possíveis modos potenciais de falha e determinar o efeito de cada uma sobre o desempenho do sistema, mediante um raciocínio basicamente dedutivo. Sendo, portanto, um método analítico padronizado para detectar e eliminar problemas potenciais de forma sistemática e completa.

A ferramenta sistematiza grupos de atividades visando detectar possíveis falhas e avaliar os efeitos das mesmas tanto para projetos do produto como para projetos do processo. Após identificadas as possíveis falhas, ações podem ser definidas e tomadas visando reduzir ou eliminar a probabilidade de ocorrência ou aumentar a probabilidade de deteç̧ão das falhas.
No FMEA três características precisam ser compreendidas: modos de falha, efeito e causas. Segundo Gomes [4]

\begin{abstract}
Modos de falha são eventos que levam, associados a eles, uma diminuição total ou parcial da função do produto ou processos e de suas metas de desempenho. Os efeitos podem ser entendidos como as formas como os modos de falha podem afetar 0 desempenho do sistema do ponto de vista do "cliente", onde como cliente, pode-se entender o próximo processo por onde o produto tenha que passar caso seja uma análise de processos. Já as causas da falha são os eventos que geram o aparecimento do modo de falha.
\end{abstract}

Adicionalmente, outras compreensões importantes são dos índices de ocorrência, gravidade, detecção e risco.

- Índice de ocorrência (O): é uma estimativa das probabilidades combinadas de ocorrer uma causa de falha e consequentemente resultar no tipo de falha no produto ou processo, quanto maior a probabilidade de ocorrer, maior será seu valor.

- Índice de gravidade $(G)$ : reflete o quanto o efeito da falha impacta o cliente assumindo que essa falha ocorra, ou seja, qual a gravidade desta falha para o cliente, quanto maior o impacto, maior será o seu valor.

- Índice de detecção (D): representa a probabilidade de a falha ser detectada antes de chegar ao cliente e deve ser atribuída baseando-se no conjunto modo de falha e efeito, bem como nos controles atuais que estão sendo exercidos. Quanto maior for a probabilidade de detecção, menor será o seu valor.

Em geral, são utilizados os valores de 1 a 9 para os índices de ocorrência, gravidade e detecção. Já o índice de risco é obtido por meio da multiplicação dos três índices.

Índice de risco $=$ Ocorrência $\mathrm{x}$ Gravidade $\mathrm{x}$ Detecção

Quanto maior for o valor do risco em relação às diversas causas, maior deve ser a atenção dada para a resolução do problema e mais urgente a alocação de recursos para eliminá-lo ou diminuir a sua probabilidade de ocorrência. 


\subsubsection{Gráficos de controle}

Gráficos de controle são ferramentas que dispõem dados de forma a permitir a identificação de quando o processo está sob controle ou fora de controle. De acordo com Helman e Andery [5], o gráfico de controle é normalmente utilizado para detectar causas especiais e causas comuns.

De acordo com Montgomery [6], causas comuns são aquelas que tem um efeito cumulativo de causas não controláveis, como por exemplo temperatura e umidade. Já as causas especiais são falhas ocasionais que podem acontecer durante o processo, como erros de operação ou erros de máquina. O objetivo é desenvolver uma estratégia de controle para o processo que permita separar eventos relacionados a causas especiais de eventos relacionados a causas comuns. Desta forma, para um dado processo, um gráfico de controle pode indicar a ocorrência de causas especiais de variação. De acordo com Siqueira (1997), a definição do tamanho e do número de subgrupos necessários à construção de gráficos de controle não segue regras estabelecidas, devendo serem analisadas o custo de inspeção, o volume produzido e a importância da informação.

A coleta de dados é de extrema importância na utilização do gráfico de controle, devendo garantir-se que os mesmos sejam confiáveis para que em seguida os limites de controle possam ser calculados. Se espera que enquanto apenas causas comuns estejam presentes no processo, os pontos não fiquem fora dos limites superior e inferior de controle.

Quando um ponto cai fora dos limites de controle é então provável que causas especiais tenham ocorrido no processo, devendo ser investigado o motivo para eliminá-las, retornando o processo a um estado de controle. Exemplos de processos sob controle e fora de controle podem ser observados na Figura 1.

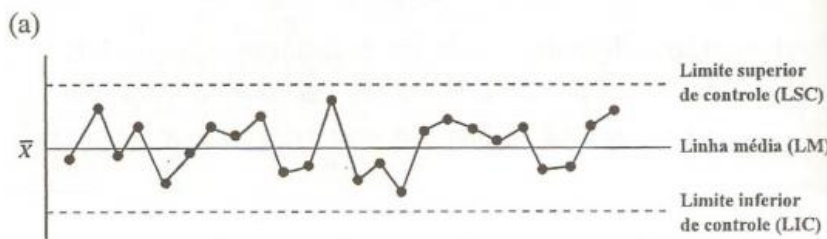

(b)

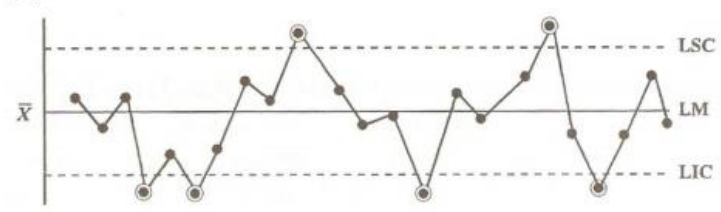

(a) Processo sob controle

(b) Processo fora de controle.

Figura 1 - Exemplo de gráfico de um processo sob controle e fora de controle.

Fonte: [7]

Os gráficos de controle podem ser divididos em gráficos de controle por variáveis e gráficos de controle por atributo. Após coletados os dados em pequenos grupos de tamanhos constantes, espera-se que a variabilidade entre as amostras seja primeiramente devido a causas comuns. Por este motivo, a frequência de amostragem deve ser escolhida de modo a aumentar a chance de ocorrerem diferenças entre as amostras. Em seguida, os limites de controle podem ser calculados.

Em gráficos de controle por atributo, os atributos são características comparadas a certo padrão podendo assumir então apenas valores discretos. Neste trabalho, utiliza-se a classificação de conforme ou não conforme. Em geral, os atributos necessitam menos especialização da mão de obra para coleta dos dados do que os gráficos de controle por variável.

Devido a essa característica dos gráficos de controle por atributo e também pela preocupação com a dificuldade de garantir uma alta confiabilidade de dados para a construção de gráfico de controle por variáveis para o processo observado, optou-se por utilizar no presente trabalho um gráfico de controle por atributo, mais especificamente, o gráfico de controle por fração defeituosa ( $p)$.

De acordo com Montgomery [6], os princípios estatísticos subjacentes ao gráfico de controle para fração não conforme se baseia na distribuição binomial. Tendo em vista um processo operando continuamente e de forma estável, de modo que a probabilidade de que uma 
unidade não esteja de acordo com as especificações seja p, e que as sucessivas unidades produzidas sejam independentes, então cada unidade a ser produzida é uma realização de uma variável aleatória de Bernoulli com parâmetro p. Se tirarmos uma amostra aleatória de $\mathrm{n}$ unidades do produto e se $\mathrm{D}$ é o número de unidades do produto que são não conformes, então $D$ tem uma distribuição binomial com parâmetros n e p, de acordo com a Equação (1).

$$
\begin{gathered}
P\{D=x\}=\left(\begin{array}{l}
n \\
x
\end{array}\right) p^{x}(1-p)^{n-x} \\
x=0,1, \ldots, n
\end{gathered}
$$

A média e a variância da variável aleatória $D$ são $n p$ e $n p(1-p)$, respectivamente. A fração amostral não conforme é definida como a razão entre o número de unidades não conformes na amostra $D$ e o tamanho $\mathrm{n}$ da amostra, ou seja: $\widehat{p}=\frac{D}{n}$.

Com isso, os gráficos de controle para a fração não conforme podem ser criados. Portanto, o nome "gráfico $\mathrm{p}$ " é concebido pelo fato deste gráfico monitorar a fração não conforme do processo, $p$, e os seus limites de controle são dados na Equação (2).

$$
\begin{gathered}
L S C=p+\sqrt{\frac{p(1-p)}{n}} \\
L M=L C=p \\
L I C=p-\sqrt{\frac{p(1-p)}{n}}
\end{gathered}
$$

Vale ressaltar ainda que a depender do processo a ser observado, nem sempre o tamanho amostral será constante. No presente trabalho o problema estudado tem tamanho amostral variável, pois os lotes de peças programados dependem da programação de equipamentos a serem montados na linha de produção. No caso de um tamanho amostral variável usa-se a média entre os " $n$ ", ou seja: $\bar{n}=\frac{\left(n_{1}+\ldots+n_{m}\right)}{m}$.

\section{METODOLOGIA}

Este trabalho apresenta um projeto de redução de sucata implementado em uma indústria metalúrgica em Pernambuco no ramo de produção de refrigeradores para uso comercial.

O estudo foi realizado através da coleta de dados durante um ano e implementações de melhorias ao longo do mesmo com o objetivo de reduzir o volume de não conformidades de peças produzidas com chapas de aço na principal máquina da fábrica. Para isso, foram utilizadas ferramentas da qualidade como Gráfico de controle e FMEA.

Como a máquina produz três tipos de peças com variados modelos entre eles, os gráficos de controle foram divididos em tipo 1, tipo 2 e tipo 3 analisados trimestralmente cada uma.

Gráficos de controle de atributo por fração defeituosa foram aplicados visando verificar se 0 processo está ou não sob controle. Caso pontos fora de controle fossem identificados, os mesmos serviriam de dados de entrada para o FMEA para serem analisados os índices de risco e consequentemente melhorias fossem propostas.

\section{RESULTADOS E DISCUSSÕES}

No final de 2016 foi evidenciado um alto percentual de sucateamento de peças na principal máquina da fábrica que apesar de ser relativamente nova, começava a apresentar alguns defeitos. Com isso, um banco de dados foi criado para apontamento de não conformidades, com o intuito de ser utilizado para criar gráficos de controle por atributo de percentual defeituoso.

As peças produzidas foram divididas em três tipos que chamaremos respectivamente de tipo 1 (fundos), tipo 2 (travessas) e tipo 3 (pés). Cada tipo de peça foi analisado trimestralmente e um gráfico de controle foi criado para cada uma. Cada vez que um ponto fora de controle foi identificado a causa foi investigada e aplicada ao FMEA.

Com o intuito de não colocar várias tabelas no presente trabalho ocupando muito espaço, apenas os respectivos gráficos de controle serão incluídos como forma de demonstrar os dados.

O tamanho amostral de cada gráfico variou entre 32 e 59 a depender do volume de produção em cada trimestre, além disso, os lotes eram programados de acordo com a necessidade de cada peça na linha de produção, não sendo possível definir um tamanho amostral fixo e por isso o gráfico de controle por percentual 


\section{Aplicação de FMEA e CEP para redução de sucata em uma indústria metalúrgica}

defeituoso com média amostral variável foi utilizado.

Primeiramente, todos os dados trimestrais serão apresentados para em seguida detalhar as ações recomendadas e tomadas do FMEA que tiveram impacto na redução das não conformidades serem apresentadas.

\subsection{Peça tipo 1}

\subsubsection{PEÇA TIPO 1 - PRIMEIRO TRIMESTRE}

- Tamanho amostral $=45$;

- Média amostral $=177,4$;

- Percentual defeituoso " $p "=4,65 \%$;

- $\quad$ LC $=4,65 \%$; LSC =9,39\%; LIC = 0;

- Pontos fora de controle $=3$.

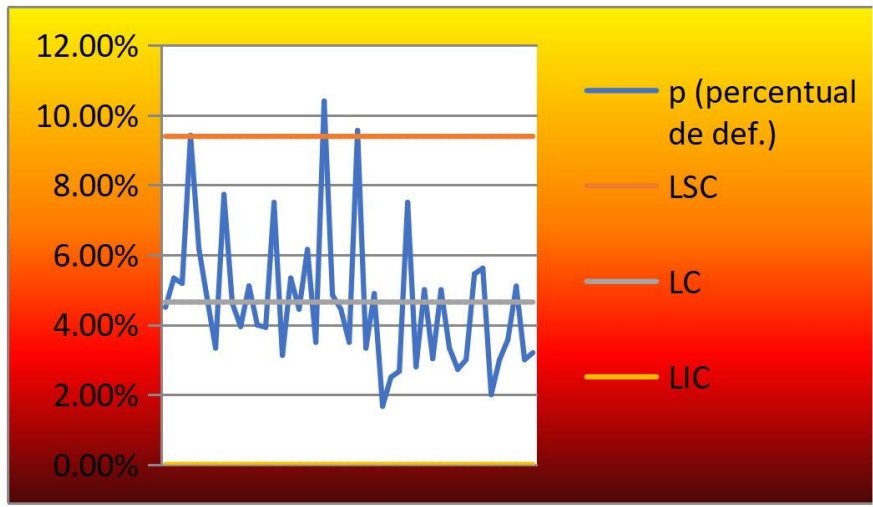

Figura 2: Gráfico de controle - fundos (primeiro trimestre).

Fonte: Autor.

\subsubsection{PEÇA TIPO 1 - SEGUNDO TRIMESTRE}

- Tamanho amostral $=37$;

- Média amostral $=165,92$;

- Percentual defeituoso " $p "=3,26 \%$;

- $\mathrm{LC}=3,26 \%$; $\mathrm{LSC}=7,40 \%$; $\mathrm{LIC}=0$;

- Pontos fora de controle $=1$.

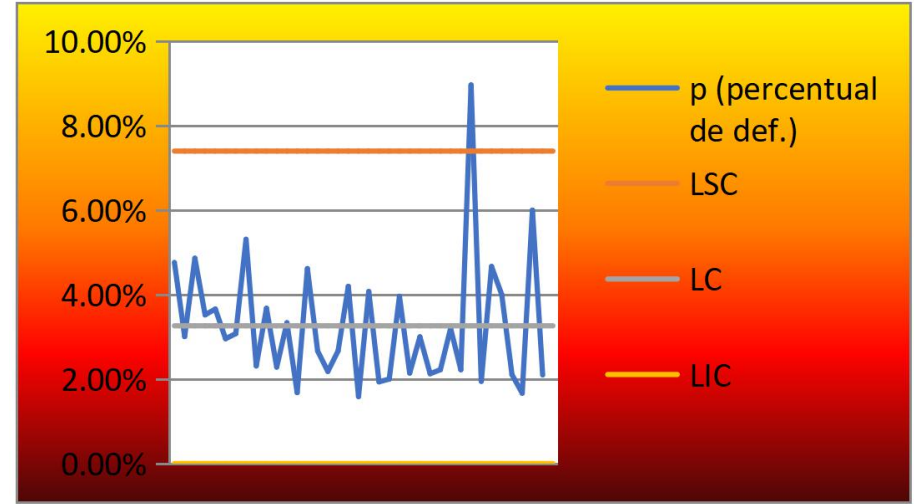

Figura 3: Gráfico de controle - fundos (segundo trimestre).

Fonte: Autor.

\subsubsection{PEÇA TIPO 1 - TERCEIRO TRIMESTRE}

- Tamanho amostral $=34$;

- Média amostral = 150,71;

- Percentual defeituoso " $p "=2,37 \%$;

- $\mathrm{LC}=2,37 \%$; LSC = 6,09\%; LIC = 0;

- Pontos fora de controle $=0$.

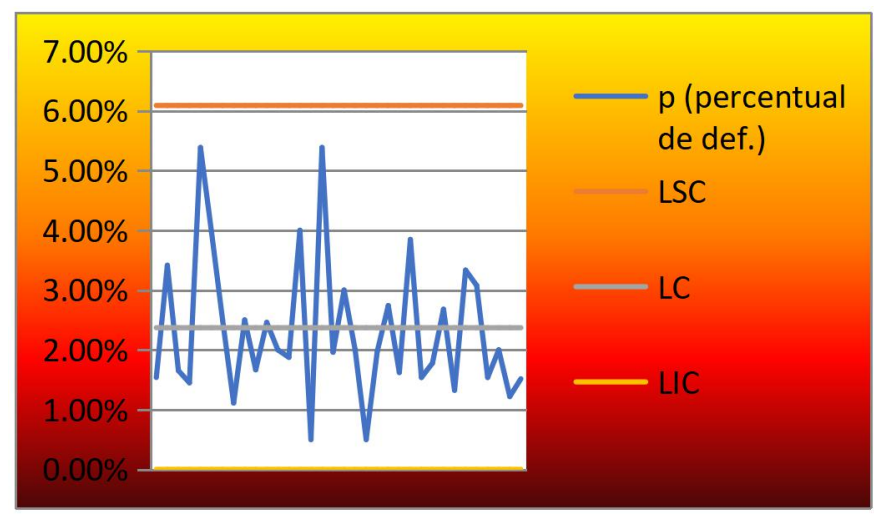

Figura 4: Gráfico de controle - fundos (terceiro trimestre).

Fonte: Autor.

\subsubsection{PEÇA TIPO 1 - QUARTO TRIMESTRE}

- Tamanho amostral $=32$;

- Média amostral = 161,84;

- Percentual defeituoso " $p "=1,93 \%$;

- $\mathrm{LC}=1,93 \%$; LSC = 5,18\%; LIC = 0;

- Pontos fora de controle $=0$. 


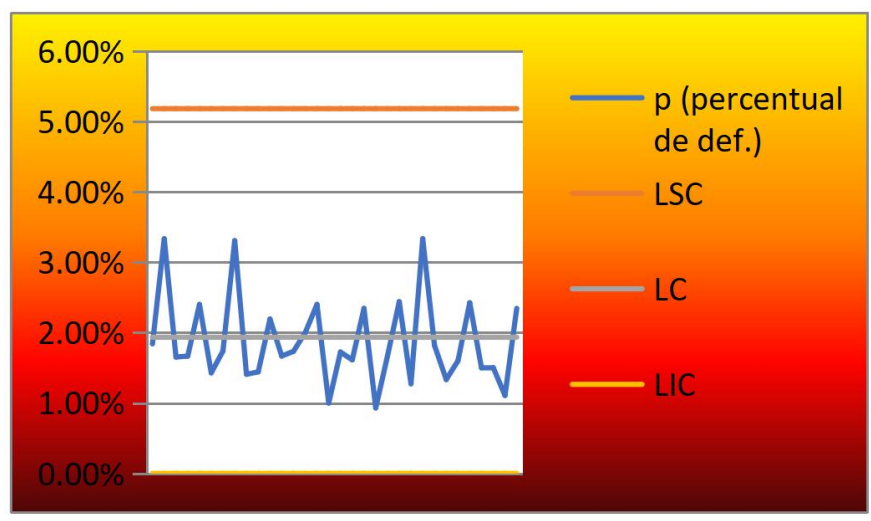

Figura 5: Gráfico de controle - fundos (quarto trimestre).

Fonte: Autor.

\subsection{Peça tipo 2}

\subsubsection{PEÇA TIPO 2 - PRIMEIRO TRIMESTRE}

- Tamanho amostral = 59;

- Média amostral = 257,51;

- Percentual defeituoso "p" = 4,41\%;

- $\mathrm{LC}=4,41 \%$; LSC = 8,25\%; LIC = 0;

- Pontos fora de controle $=3$.

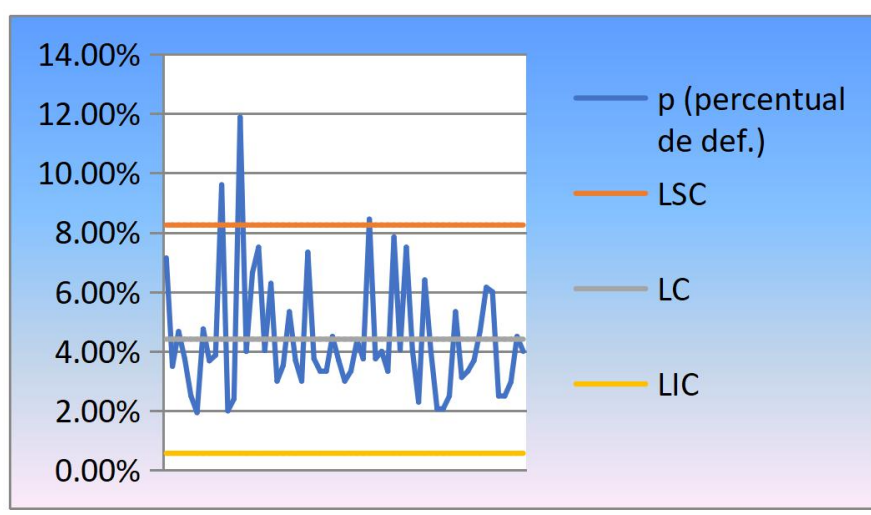

Figura 6: Gráfico de controle - travessas (primeiro trimestre).

Fonte: Autor.

\subsubsection{PEÇA TIPO 2 - SEGUNDO TRIMESTRE}

- Tamanho amostral = 59;

- Média amostral = 202,67;

- Percentual defeituoso "p" = 3,70\%;

- $\mathrm{LC}=3,70 \%$; LSC = 7,67\%; LIC = 0;

- Pontos fora de controle $=1$.

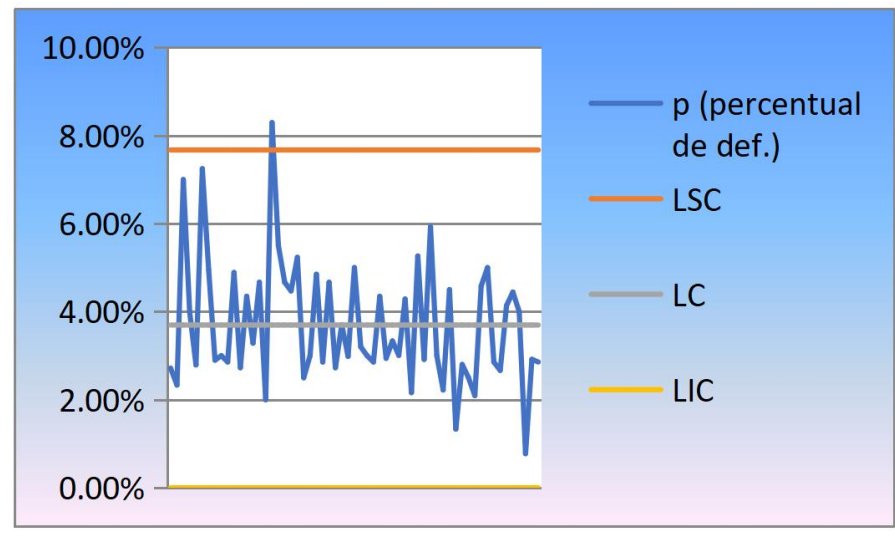

Figura 7: Gráfico de controle - travessas (segundo trimestre).

Fonte: Autor.

\subsubsection{PEÇA TIPO 2 - TERCEIRO TRIMESTRE}

- Tamanho amostral $=52$;

- Média amostral = 220,44;

- Percentual defeituoso " $p$ " $=2,58 \%$;

- $\mathrm{LC}=2,58 \%$; LSC = 5,78\%; LIC = 0;

- Pontos fora de controle $=0$.

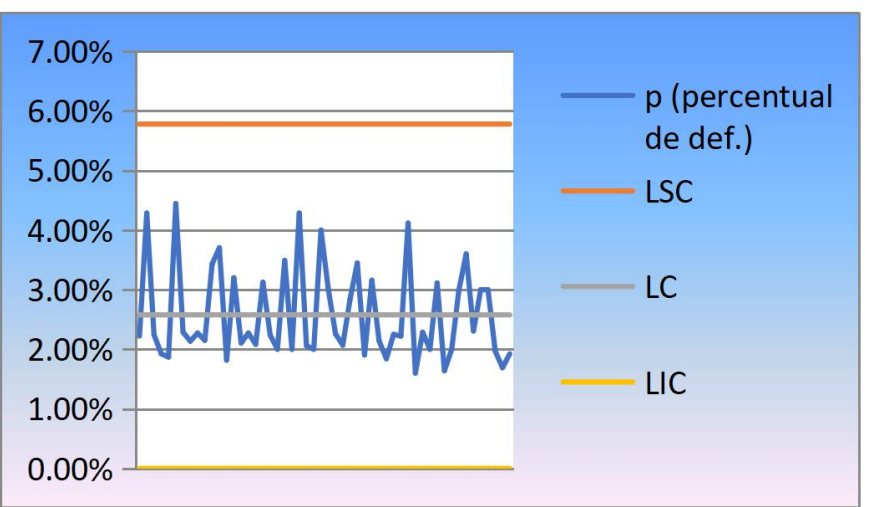

Figura 8: Gráfico de controle - travessas (terceiro trimestre).

Fonte: Autor.

\subsubsection{PEÇA TIPO 2 - QUARTO TRIMESTRE}

- Tamanho amostral $=44$;

- Média amostral = 225,82;

- Percentual defeituoso " $p$ " $=2,03 \%$;

- $\mathrm{LC}=2,03 \%$; LSC = 4,84\%; LIC =0;

- Pontos fora de controle $=0$. 


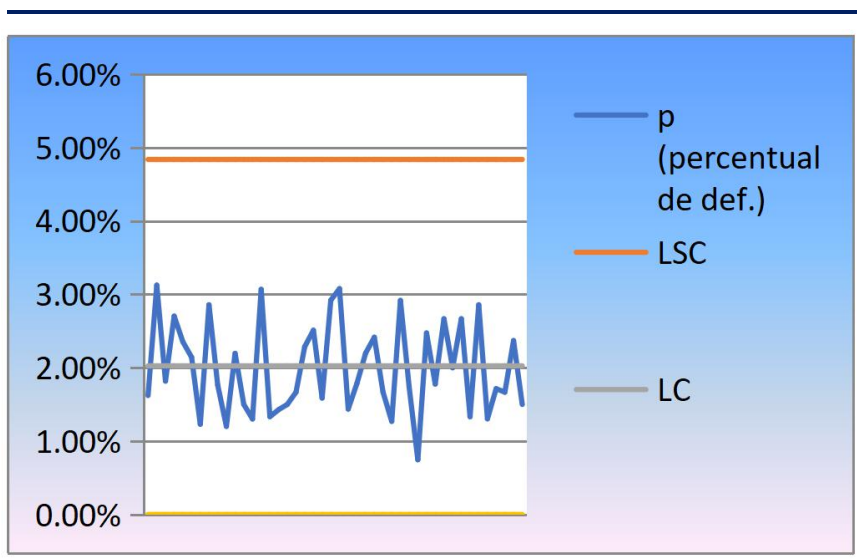

Figura 9: Gráfico de controle - travessas (quarto trimestre).

Fonte: Autor.

\subsection{Peça tipo 3}

\subsubsection{PEÇA TIPO 3 - PRIMEIRO TRIMESTRE}

- Tamanho amostral $=45$;

- Média amostral = 346,60;

- Percentual defeituoso " $\mathrm{p} "=4,94 \%$;

- $\mathrm{LC}=4,94 \%$; LSC $=8,44 \%$; LIC = 1,45\%;

- Pontos fora de controle $=4$.

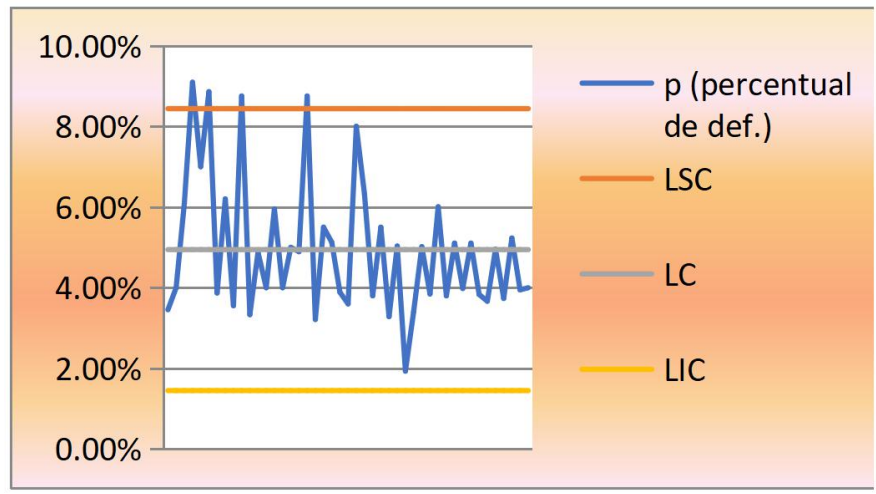

Figura 10: Gráfico de controle - pés (primeiro trimestre). Fonte: Autor.

\subsubsection{PEÇA TIPO 3 - SEGUNDO TRIMESTRE}

- $\quad$ Tamanho amostral $=36$;

- Média amostral $=288,64$;

- Percentual defeituoso " $p "=4,05 \%$;

- $\mathrm{LC}=4,05 \% ; \mathrm{LSC}=7,53 \%$; LIC $=0,57 \%$;

- $\quad$ Pontos fora de controle $=1$.

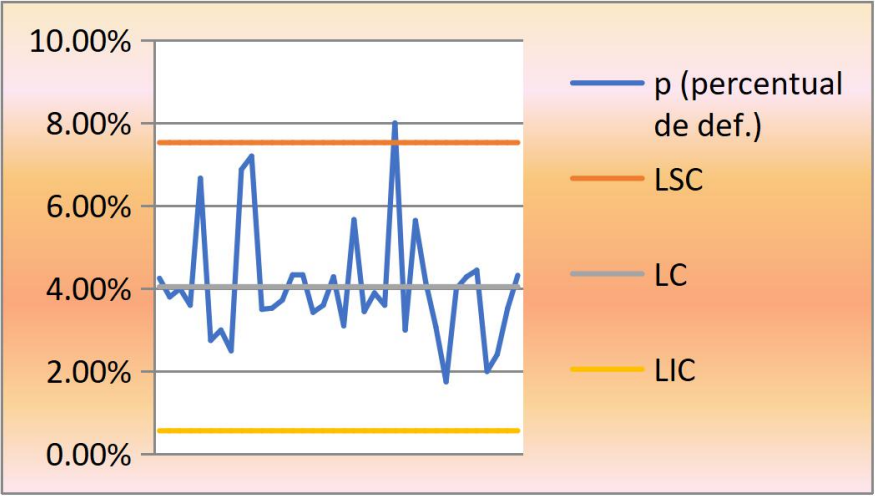

Figura 11: Gráfico de controle - pés (segundo trimestre). Fonte: Autor.

\subsubsection{PEÇA TIPO 3 - TERCEIRO TRIMESTRE}

- $\quad$ Tamanho amostral = 39;

- $\quad$ Média amostral $=299,36$;

- Percentual defeituoso " $p$ " $=2,52 \%$;

- $\quad$ LC = 2,52\%; LSC = 5,24\%; LIC = 0;

- $\quad$ Pontos fora de controle $=0$.

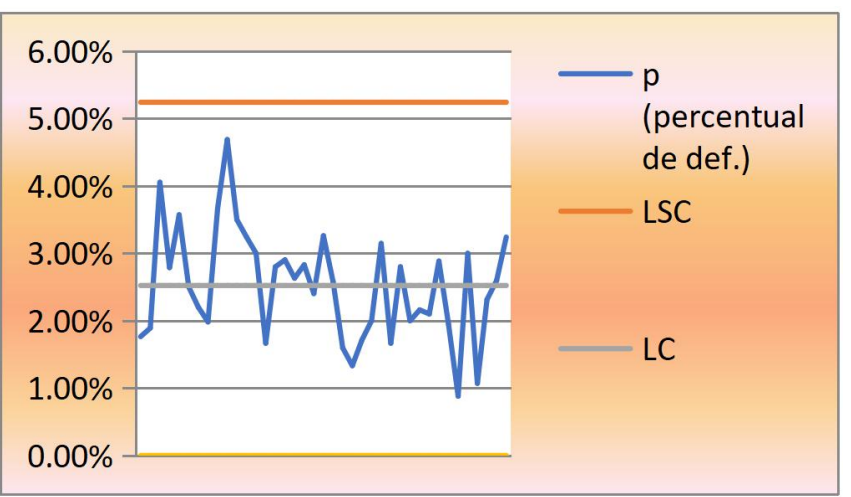

Figura 12: Gráfico de controle - pés (terceiro trimestre). Fonte: Autor.

\subsubsection{PEÇA TIPO 3 - QUARTO TRIMESTRE}

- $\quad$ Tamanho amostral = 36;

- $\quad$ Média amostral $=274,00$;

- Percentual defeituoso " $p "=2,07 \%$;

- $\quad \mathrm{LC}=2,07 \%$; LSC $=4,66 \%$; LIC $=0$;

- $\quad$ Pontos fora de controle $=0$. 


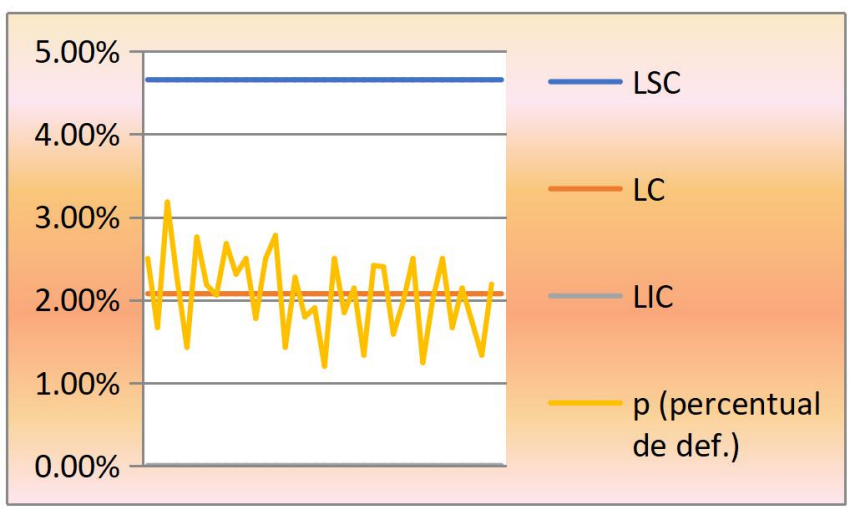

Figura 13: Gráfico de controle - pés (quarto trimestre). Fonte: Autor.

\subsection{Análise de dados e aplicação de FMEA}

Como pode ser observado nos primeiros trimestres de cada gráfico, a maioria dos pontos fora de controle foram resolvidos no segundo trimestre. A partir de uma análise dos pontos fora de controle, o quadro 1 mostra as causas que foram destacadas no primeiro trimestre.

Já no segundo trimestre, apenas um problema foi reincidente, devido a uma falha operacional de posicionamento de ventosas causada por um operador novato. $\mathrm{O}$ quadro 2 destaca os pontos fora de controle do segundo trimestre.

Tabela 1: Causas (primeiro trimestre).

\begin{tabular}{|c|c|c|c|c|}
\cline { 2 - 5 } \multicolumn{1}{c|}{} & $\begin{array}{c}\text { Peça } \\
\text { tipo 1 }\end{array}$ & $\begin{array}{c}\text { Peça tipo } \\
\mathbf{2}\end{array}$ & $\begin{array}{c}\text { Peça } \\
\text { tipo 3 }\end{array}$ & TOTAL \\
\hline $\begin{array}{c}\text { Falha na ventosa } \\
\text { (braço } \\
\text { alimentador) }\end{array}$ & $\mathbf{1}$ & $\mathbf{1}$ & $\mathbf{2}$ \\
\hline $\begin{array}{c}\text { Falha na ventosa } \\
\text { (eixo de rotação } \\
\left.180^{\circ}\right)\end{array}$ & $\mathbf{2}$ & $\mathbf{1}$ & $\mathbf{2}$ & $\mathbf{3}$ \\
\hline $\begin{array}{c}\text { Falha em } \\
\text { sensores }\end{array}$ & $\mathbf{2}$ & $\mathbf{1}$ & $\mathbf{3}$ \\
\hline $\begin{array}{c}\text { Falha na dobra } \\
\text { V4 }\end{array}$ & & & & \\
\hline
\end{tabular}

Fonte: Autor.

Tabela 2: Causas (segundo trimestre).

\begin{tabular}{|c|c|c|c|c|}
\cline { 2 - 5 } \multicolumn{1}{c|}{} & $\begin{array}{c}\text { Peça } \\
\text { tipo 1 }\end{array}$ & $\begin{array}{c}\text { Peça } \\
\text { tipo 2 }\end{array}$ & $\begin{array}{c}\text { Peça } \\
\text { tipo 3 }\end{array}$ & TOTAL \\
\hline $\begin{array}{c}\text { Falha na ventosa } \\
\text { (braço alimentador) }\end{array}$ & & & $\mathbf{1}$ & $\mathbf{1}$ \\
\hline $\begin{array}{c}\text { Chapa fora de } \\
\text { esquadro ou } \\
\text { medida }\end{array}$ & $\mathbf{1}$ & $\mathbf{1}$ & & $\mathbf{2}$ \\
\hline
\end{tabular}

Fonte: Autor.
No terceiro e quarto trimestres nenhum ponto fora de controle foi observado.

Apesar de ser aplicado trimestralmente, apenas a tabela final do FMEA será incluída nos apêndices contendo todas as causas (pontos fora de controle) com o intuito de facilitar a compreensão deste trabalho. A seguir, as recomendações propostas e aplicadas mediante aplicação do FMEA (Apêndice 1) serão detalhadas.

Os índices utilizados foram de 1 a 9, portanto, temos um fator geral de risco máximo de $9^{3}=$ 729. Como pode ser observado no Apêndice 1, os níveis gerais de riscos só não se mostraram tão elevados devido a um nível de detecção relativamente baixo, ou seja, as causas são relativamente fáceis de serem identificadas.

Adicionalmente, apesar de não haver riscos a saúde e segurança dos colaboradores, a gravidade foi máxima e definida como 9 em todos os casos levando em conta o impacto direto na peça, ou seja, qualquer uma das coisas leva a peça ao sucateamento.

\subsubsection{CAUSA 1 - FALHA NA VENTOSA (BRAÇO ALIMENTADOR)}

A recomendação 1 está relacionada a falha na ventosa do braço alimentador e foi verificado como o terceiro maior grau de risco no FMEA (Apêndice 1). Até o problema ser identificado não existiam controles, portanto foram criados dois tipos de controle.

O primeiro se tratava da inspeção diária do manômetro da máquina no turno da manhã. Foi observado que ocasionalmente os operadores iniciavam a máquina antes de os compressores da fábrica serem capazes de fornecer a pressão adequada de $6 \mathrm{bar}$ para seu funcionamento, causando que algumas chapas de aço caíssem quando eram movidas pelas ventosas, foi então definido que diariamente só se iniciaria a máquina quando atingisse tal pressão e essa informação adicionada a um checklist que deveria ser preenchida pelos operadores no início do turno.

O segundo controle definido foi a inspeção semanal do estado das ventosas, verificando se estavam corretamente posicionadas e se não tinha alguma ventosa rasgada. 


\subsubsection{CAUSA 2 - FALHA NA VENTOSA (EIXO DE ROTAÇÃO 180)}

A segunda recomendação também esta ligada a um problema com ventosas, porém, com as ventosas do eixo de rotação $180^{\circ}$. A causa em questão se apresentou como o segundo maior grau de risco no FMEA (Apêndice 1) e apesar de um grau de ocorrência um pouco maior devido a presença de menos ventosas nesse eixo (sem a possibilidade de serem adicionadas ventosas extras), as mesmas recomendações no item anterior servem para combater a causa atual.

\subsubsection{CAUSA 3 - FALHA EM SENSORES}

A terceira causa se destacou como o maior fator de risco entre as demais devido a um alto fator de ocorrência uma menor probabilidade de detecção. A mesma está relacionada a falhas em sensores na máquina.

Como a máquina fica ao lado do setor de pintura eletrostática, ao longo do dia o pó da pintura se dispersava no ambiente e boa parte deste pó acabava indo para os sensores da máquina, impossibilitando-os de funcionar corretamente. Isso foi constatado quando a pintura começou a funcionar em dois turnos aumentando a ocorrência de falhas nos sensores. Em curto prazo uma mangueira foi instalada com pequenas saídas de ar que funcionavam como uma barreira para que o pó fosse jogado de volta na cabine de pintura ao invés de se dispersar no ambiente. Em longo prazo se planeja isolar a pintura eletrostática por completo. Adicionalmente, foi acrescentada a atividade de limpeza de sensores diariamente no checklist.

\subsubsection{CAUSA 4 - FALHA NA DOBRA V4}

Existiam quatro tipos de dobras feitos pela máquina, sendo todos eles necessários a depender do tipo de peça produzido. Porém, foi constatado que o tipo de dobra chamado V4 comumente ocasionava problema em peças tipo 2 e tipo 3. Sendo responsáveis por um total de 3 pontos não conforme nos gráficos de controle das peças em questão. Apesar de haver um controle (inspeção), isso apenas evita que a peça seja aprovada, mas não previne que a falha ocorra e consequentemente que sucata seja gerada.
Portanto, para reduzir o percentual de sucata gerada um novo tipo de dobra chamada V5 foi criada para substituir todas as dobras V4 nas peças tipo 2 e tipo 3 .

\subsubsection{CAUSA 5 - CHAPA FORA DE ESQUADRO OU MEDIDA}

A última causa apresenta o menor fator de risco e trata de chapas fora de esquadro ou fora de medida, porém não é diretamente relacionada a máquina em questão e sim a outra máquina responsável pelo processo anterior (linha de corte).

Apesar de um baixo nível de ocorrência, como a inspeção era feita geralmente no início, no meio e no fim do corte de chapas foi implantado um aumento no número de inspeções passando agora para um total de cinco inspeções por lote de peça. Adicionalmente, o setor de manutenção foi acionado para programar manutenções preventivas nas guilhotinas da máquina mensalmente.

\subsection{Resultados}

Como pode ser observado nos gráficos de controle de cada tipo de peça no primeiro trimestre o percentual de defeitos estava pouco abaixo de $5 \%$ e em cada trimestre seguinte foi observada uma redução considerável.

A tabela 3 e 0 gráfico da figura 14 demonstram o percentual por trimestre das três peças.

A linha de tendência (Figura 14) demonstra que as ações tomadas ao longo do ano impactaram positivamente a redução de sucatas na fábrica atingindo uma média de $2,01 \%$ no quarto trimestre em contraste aos $4,67 \%$ do primeiro trimestre. Quando comparados 0 primeiro e o último mês, a redução é ainda maior, passando de $5,80 \%$ para $1,63 \%$, o que representa uma economia de aproximadamente 2,9 toneladas de chapa de aço por mês. 
Tabela 3: Percentual de defeitos por trimestre.

\begin{tabular}{|l|c|c|c|c|}
\cline { 2 - 5 } \multicolumn{1}{c|}{} & $\mathbf{1 0}^{\mathbf{0}}$ trim. & $\mathbf{2 0}^{\circ}$ trim. & $\mathbf{3 0}^{\mathbf{0}}$ trim. & $\mathbf{4}^{\circ}$ trim. \\
\hline $\begin{array}{l}\text { PEÇAS } \\
\text { TIPO 1 }\end{array}$ & $\mathbf{4 , 6 5 \%}$ & $3,26 \%$ & $\mathbf{2 , 3 7 \%}$ & $1,93 \%$ \\
\hline $\begin{array}{l}\text { PEÇAS } \\
\text { TIPO 2 }\end{array}$ & $4,41 \%$ & $3,70 \%$ & $2,58 \%$ & $2,03 \%$ \\
\hline $\begin{array}{l}\text { PEÇAS } \\
\text { TIPO 3 }\end{array}$ & $4,94 \%$ & $4,05 \%$ & $2,52 \%$ & $2,07 \%$ \\
\hline MÉDIA & $\mathbf{4 , 6 7 \%}$ & $\mathbf{3 , 6 7 \%}$ & $\mathbf{2 , 4 9 \%}$ & $\mathbf{2 , 0 1} \%$ \\
\hline
\end{tabular}

Fonte: Autor.

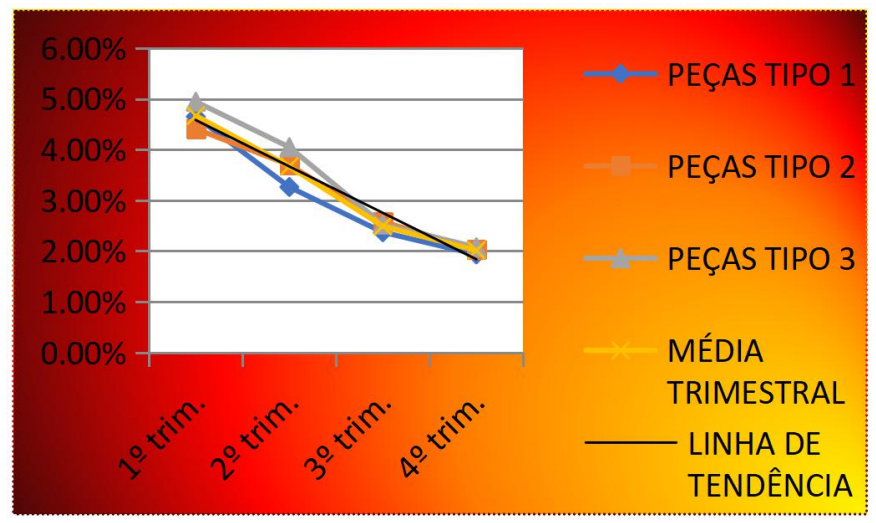

Figura 14: Médias trimestrais.

Fonte: Autor.

\section{CONCLUSÃo}

A partir deste trabalho foi possível a aplicação de ferramentas da qualidade para análise e resolução de problemas com sucateamento de chapas de aço em uma indústria metalúrgica. Ao longo do período de um ano dados foram coletados e serviram como input para a elaboração de gráficos de controle por fração não conforme com tamanho amostral variável.

Os gráficos de controle tornaram possível a identificação de causas especiais que costumavam deixar o processo fora de controle, com isso, a aplicação do FMEA permitiu realizar uma avaliação quantitativa dos índices de gravidade, ocorrência, detecção e risco de cada uma das causas especiais identificadas e foi possível então sugerir propostas para resolução dos principais problemas.

As recomendações aceitas trouxeram ao longo de um ano uma redução percentual de 5,80\% para $1,63 \%$ quando comparados o primeiro e o último mês, representando aproximadamente 2,9 toneladas de chapa de aço por mês.

\section{REFERÊNCIAS}

[1] CARPINETTI, L. C. R. Gestão da qualidade - Conceitos e Técnicas. 2. ed. São Paulo: Atlas, 2012.

[2]CHIAVENATO, I. Introdução à Teoria Geral da Administração. 7. ed. Rio de Janeiro: Elsevier, 2003.

[3]BEST, Mark; NEUHAUSER, Duncan. Walter A Shewhart, 1924, and the Hawthorne factory. BMJ Quality \& Safety, v. 15, n. 2, p. 142143, 2006.

[4] GOMES, F. V. Aplicação de ferramentas da qualidade para identificação de causas e propostas de melhoria para o sucateamento em uma indústria no setor de refrigeração. Monografia (Graduação em Engenharia de Produção) - Universidade Federal de Pernambuco, Recife, 2015.

[5] HELMAN, H.; ANDERY, P. R. P. Análise de falhas (aplicação dos métodos de FMEA FTA). Belo Horizonte: Fundação Christiano Ottoni, 1995. Série ferramentas da qualidade, v. 11 .

[6] MONTGOMERY, D. C. Introdução ao controle estatístico da qualidade. Rio de Janeiro: Performa, 2004.

[7] WERKEMA, M. C. C. Ferramentas estatísticas básicas para 0 gerenciamento de processos. Belo Horizonte: Fundação Christiano Ottoni, v. 2, 1995.

[8] SHEWHART, Walter A.; DEMING, W. Edwards. In Memoriam: Walter A. Shewhart, 18911967. The American Statistician, v. 21, n. 2, p. 39-40, 1967. DOI: https://doi.org/10.1080/00031305.1967.1048 1808.

[9] FEIGENBAUM, A. V. Total Quality Control. 3. ed. New York: McGraw-Hill, 1986.

[10] GARVIN, D. Managing Quality: The Strategic and Competitive Edge. New York: The Free Press, 1988.

[11] JURAN, J. M. A history of managing for quality: The evolution, trends, and future directions of managing for 
quality. Milwaukee: ASQC Quality press, 1995.

[12] KUMAR, A.; MANTHA, S. S. Scrap reduction by using total quality management tools. International Journal Of Industrial Engineering - Theory Applications AndPractice, Cincinnati, Ohio, 2009, v.16, p.6.

[13] SHEWART, W. A; DEMING, E. W. Statistical Method from the Viewpoint of Quality

Control. New York: Dover Publications, 1986. 
Revista de Engenharia e Pesquisa Aplicada, v. 4, n. 3, p. 11-23, 2019

APÊNDICES

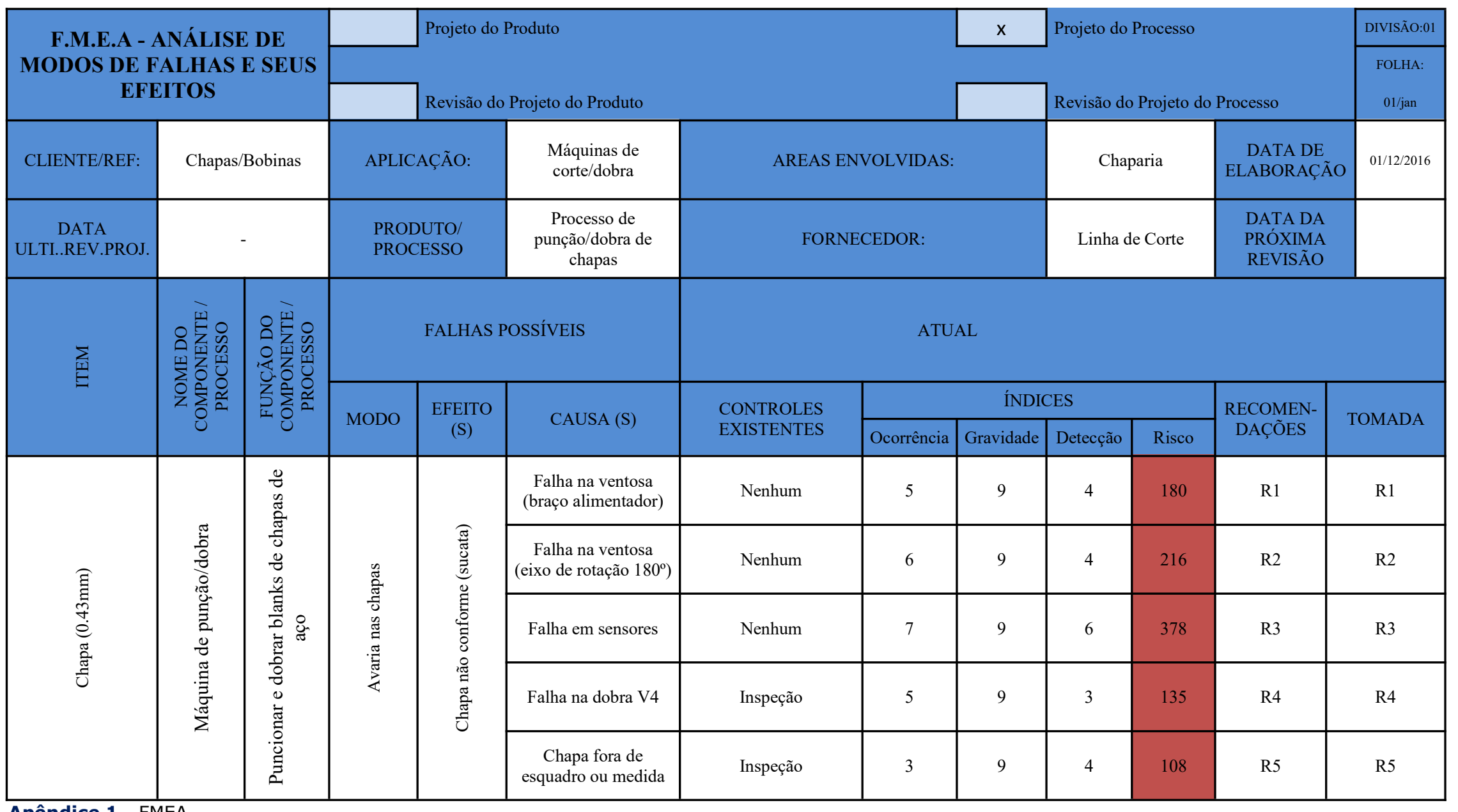

Apêndice 1 - FMEA 